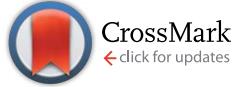

Cite this: RSC Adv., 2017, 7, 3888

Received 25th November 2016 Accepted 30th November 2016

DOI: 10.1039/c6ra27307f

www.rsc.org/advances

\section{Photocatalyzed iron-based ATRP of methyl methacrylate using 1,3-dimethyl-2- imidazolidinone as both solvent and ligand}

\begin{abstract}
Jian Wu, Lifen Zhang, ${ }^{*}$ Zhenping Cheng* and Xiulin Zhu
Photochemistry serves as a wonderful means to facilitate various chemical reactions and is indeed unique in its powerful ability to meet the energetic requirements for conducting processes that would not be accomplished using thermal counterparts. In this work, a novel photocatalyzed Fe-based atom transfer radical polymerization (ATRP) of methyl methacrylate (MMA) was performed under UV irradiation, using ethyl 2-bromophenylacetate (EBPA) as the initiator, $\mathrm{FeBr}_{2}$ as the catalyst and 1,3-dimethyl-2imidazolidinone (DMI) as both the solvent and ligand. The rate of the polymerization was relatively fast, as monomer conversion reached $91.2 \%$ at room temperature under $U V$ irradiation $\left(900 \mu \mathrm{W} \mathrm{cm}{ }^{-2}\right)$ at $360 \mathrm{~nm}$ within $26 \mathrm{~h}$. Even when the target degree of polymerization was up to 1000, the molecular weight distribution obtained remained narrow and the molecular weight $\left(M_{n, G P C}\right)$ was close to the corresponding theoretical value $\left(M_{n, t h}\right)$. The polymerization kinetics was studied in detail and the "living" features of this system were confirmed by performing successful chain extension experiments.
\end{abstract}

\section{Introduction}

Since its discovery, reversible deactivation radical polymerization (RDRP) ${ }^{1}$ has been used to synthesize well-defined polymers with various complex architectures. Atom transfer radical polymerization (ATRP), ${ }^{2}$ as one of the most widely used methods of RDRP, has gained more intensive attention. In addition to normal ATRP, several heterogeneous ATRP reactions have been reported to date, such as reverse ATRP, ${ }^{3}$ activators generated by electron transfer (AGET) ATRP, ${ }^{4}$ initiators for continuous activator regeneration (ICAR) ATRP, ${ }^{5}$ and the very recently developed photo-induced metal-free ATRP. ${ }^{6}$ The key process in ATRP is the reversible redox reaction between the alkyl halide and the active catalysts. Taking a metal complex as an example, a low oxidation transition metal complex (activator) reacts with the initiator, and generates an active radical and a corresponding high oxidation metal complex (deactivator). The active radical acts on the monomer and forms a propagating radical, and therefore the propagating radical continuously proliferates until it has been deactivated by the deactivator. The polymerization process can be controlled due to the dynamic equilibrium of the redox reaction between the low and high oxidation transition metal complexes, thus

Suzhou Key Laboratory of Macromolecular Design and Precision Synthesis, Jiangsu Key Laboratory of Advanced Functional Polymer Design and Application, State and Local Joint Engineering Laboratory for Novel Functional Polymeric Materials, Department of Polymer Science and Engineering, College of Chemistry, Chemical Engineering and Materials Science, Soochow University, Suzhou 215123, China. E-mail: chengzhenping@suda.edu.cn; zhanglifen@suda.edu.cn maintaining a low concentration of propagating radicals in the polymerization system.

Many metal catalysts can be applied in ATRP, the most common metals being $\mathrm{Cu},{ }^{7} \mathrm{Ni}^{,}{ }^{8} \mathrm{Ru}^{7 a, b}$ and $\mathrm{Fe} .{ }^{9}$ Compared to other metal catalysts, Fe-based catalysts have many attractive characteristics. Iron is the most plentiful metal on earth and possesses a low toxicity. Therefore, it is not limited in largescale industrial production, especially in the field of biomedical materials. Typical ligands used in iron catalysts are phosphorus-containing ligands,$^{10}$ nitrogen-containing ligands, ${ }^{9 c, 11}$ organic acids ${ }^{12}$ and polyethylene glycols. ${ }^{13}$ In addition, some polar solvents can also be employed as the ligand in Fe-based ATRP systems. ${ }^{14}$

Photochemistry serves as a wonderful technique to enable various chemical reactions and is indeed unique in its powerful ability to meet the energetic requirements for conducting processes that would not be accomplished using thermal counterparts. Recently, photo-induced polymerization has attracted the attention of a large number of scientists, since the ability to perform photochemical reactions under mild conditions may overcome certain problems, such as the exorbitant temperature required in thermal polymerization. In 2012, Hawker's group reported a living radical polymerization through external visible light stimulation using $\operatorname{Ir}(\mathrm{ppy})_{3}$ as the catalyst. ${ }^{15}$ In the same year, Matyjaszewski's group reported a photo-induced ATRP using a $\mathrm{Cu}$ complex as the catalyst. ${ }^{16}$ In 2015, a simple photo-induced Fe-based ATRP was reported by Matyjaszewski's group. ${ }^{17}$ However, the hyper-toxic solvent (MeCN) used in the polymerization reaction makes the whole system imperfect. Furthermore, the polymerization rate was 
a little slow (monomer conversion was less than $60 \%$ after polymerization for $28 \mathrm{~h}$ ) and the molecular weights were lower than the theoretical values, especially in the later stages of the polymerization reaction.

We know that 1,3-dimethyl-2-imidazolidinone $(\mathrm{DMI})^{18}$ is an aprotic polar solvent due to the strong electron-withdrawing effect of the carbonyl group. It exhibits low toxicity and is nearly harmless to the human body. Moreover, it exhibits good solubility and excellent stability, and has therefore been used widely in chemical synthesis.

Herein, the "green" polar solvent 1,3-dimethyl-2imidazolidinone (DMI) was employed both as the solvent and ligand (without any other additional ligands) in a photo-induced Fe-based ATRP at room temperature, using $\mathrm{FeBr}_{2}$ as the catalyst, ethyl 2-bromophenylacetate (EBPA) as the initiator and methyl methacrylate (MMA) as the model monomer under UV irradiation $\left(900 \mu \mathrm{W} \mathrm{cm}{ }^{-2}\right)$. The polymerization system exhibited a relatively fast rate of polymerization and could be controlled well, even under a 1000 target degree of polymerization.

\section{Experimental section}

\subsection{Materials}

The monomer, methyl methacrylate (MMA, +99\%), was purchased from Shanghai Chemical Reagents Co. Ltd (Shanghai, China). It was purified via removing the inhibitor by passing it through a short neutral alumina column before use. The following materials were used as received: ethyl 2-bromophenylacetate (EBPA, 97\%) purchased from J\&K Scientific Ltd, tetrahydrofuran (THF, analytical reagent) purchased from Nanjing Chemical Reagent Co. Ltd, 1,3-dimethyl-2-imidazolidinone (DMI, $98 \%)$, iron(II) bromide (98\%) and triphenylphosphine $\left(\mathrm{PPh}_{3}\right.$, 98\%) purchased from Energy Chemical, iron(III) acetylacetonate $\left(\mathrm{Fe}(\mathrm{acac})_{3}, 99.95 \%\right)$ purchased from Aldrich (Shanghai, China), toluene (analytical reagent) purchased from Chinasun Specialty Products Co. Ltd, and ascorbic acid (AsAc) purchased from Shanghai Chemical Reagents Co. Ltd (Shanghai, China).

\subsection{Characterization}

The number-average molecular weight $\left(M_{\mathrm{n}, \mathrm{GPC}}\right)$ and molecular weight distribution $\left(M_{\mathrm{w}} / M_{\mathrm{n}}\right)$ values of the resultant polymers were determined by employing a TOSOH HLC-8320 gel permeation chromatograph (GPC) equipped with a refractive-index detector (TOSOH), using TSKgel guardcolumn SuperMP-N (4.6 $\times 20 \mathrm{~mm})$ and two TSKgel SupermultiporeHZ-N $(4.6 \times 150 \mathrm{~mm})$ with a measurable molecular weight range of $5 \times 10^{2}$ to $5 \times$ $10^{5} \mathrm{~g} \mathrm{~mol}^{-1}$. THF was used as the eluent at a flow rate of $0.35 \mathrm{~mL}$ $\min ^{-1}$ and $40{ }^{\circ} \mathrm{C}$. GPC samples were injected using a TOSOH plus autosampler and calibrated with PMMA standards purchased from TOSOH. Matrix assisted laser desorption/ ionization time-of-flight mass (MALDI-TOF-MS) spectra were recorded using an UltrafleXtreme MALDI-TOF mass spectrometer equipped with a $1000 \mathrm{~Hz}$ smart beam-II laser. Fluorescence emission spectra were obtained using a quart cuvette on a Hitachi F-4600 fluorescence spectrophotometer at room temperature. The ${ }^{1} \mathrm{H}$ NMR spectrum of the obtained polymers was recorded on a Bruker $300 \mathrm{MHz}$ nuclear magnetic resonance (NMR) instrument using deuterated dimethyl sulphoxide (DMSO-d6) as the solvent and tetramethylsilane (TMS) as the internal standard at ambient temperature.

\subsection{General procedure for photo-induced Fe-based ATRP}

A typical polymerization procedure for the system with a molar ratio of $[\mathrm{MMA}]_{0}:[\mathrm{EBPA}]_{0}:\left[\mathrm{FeBr}_{2}\right]_{0}=100: 1: 1$ is as follows. A mixture was obtained by adding $\mathrm{FeBr}_{2}\left(20.4 \mathrm{mg}, 9.4 \times 10^{-5}\right.$ mol), MMA (1.0 mL, $\left.9.4 \times 10^{-3} \mathrm{~mol}\right)$, EBPA $\left(16.6 \mu \mathrm{L}, 9.4 \times 10^{-5}\right.$ mol), DMI $(0.5 \mathrm{~mL})$ and a magnetic stirring bar to a clean ampoule. The mixture was thoroughly bubbled with argon for $20 \mathrm{~min}$ to eliminate the dissolved oxygen in the reaction system, and was then flame-sealed. The polymerization reaction was carried out at room temperature under UV irradiation $(900 \mu \mathrm{W}$ $\mathrm{cm}^{-2}$ ) at $360 \mathrm{~nm}$, and the polymerization temperature was maintained through controlled fanning. After the desired polymerization time, the ampoule was opened and the contents were dissolved in a certain amount of tetrahydrofuran (THF). The resultants were precipitated by adding the solution to a large amount of hexane $(\sim 250 \mathrm{~mL})$. The polymers obtained by filtration were dried under vacuum until they reached a constant weight at $30{ }^{\circ} \mathrm{C}$. The monomer conversion was determined gravimetrically.

\subsection{Chain extension of the resultant PMMA}

A predetermined quantity of PMMA, obtained via the photoinduced Fe-based ATRP of MMA, was added to a clean ampoule, and then predetermined quantities of MMA $(1.0 \mathrm{~mL})$, $\mathrm{FeBr}_{2}(20.4 \mathrm{mg})$ and DMI $(0.5 \mathrm{~mL})$ were added. The mixture was thoroughly bubbled with argon for 20 min to eliminate the dissolved oxygen in the reaction system, and was then flamesealed. The polymerization was performed under UV irradiation $\left.(900 \mu \mathrm{W} \mathrm{cm})^{-2}\right)$ at $360 \mathrm{~nm}$ at room temperature. The rest of the procedure was the same as that for the polymerization of MMA described above. In addition, for the chain extension via the thermal polymerization method, a predetermined quantity of PMMA, obtained via the photo-induced Fe-based ATRP of MMA, was added to a clean ampoule, and then predetermined quantities of MMA $(1.0 \mathrm{~mL})$, toluene $(1.0 \mathrm{~mL}), \mathrm{Fe}(\mathrm{acac})_{3}(17.0$ $\mathrm{mg}), \mathrm{PPh}_{3}(37.0 \mathrm{mg})$ and AsAc $(66.8 \mathrm{mg})$ were added. The mixture was thoroughly bubbled with argon for $20 \mathrm{~min}$ to eliminate the dissolved oxygen in the reaction system, and was then flame-sealed. Afterwards, it was transferred into an oil bath maintained at the desired temperature $\left(90{ }^{\circ} \mathrm{C}\right)$ using a thermostat, to polymerize under stirring. After the desired polymerization time, the ampoule was placed into ice water to cool down. The rest of the procedure was the same as that for the polymerization of MMA described above.

\section{Results and discussion}

\subsection{Effect of the amount of Fe catalyst}

Firstly, we investigated the effect of the amount of $\mathrm{FeBr}_{2}$ on the polymerization of MMA, and the results are shown in Table 1. As the concentration of $\mathrm{FeBr}_{2}$ decreased (entries 1-4 in Table 1), 
Table 1 Effect of the amount of the Fe-based catalyst on the photo-induced ATRP of MMA ${ }^{a}$

\begin{tabular}{|c|c|c|c|c|c|c|c|}
\hline Entry & $x$ & $V_{\text {DMI }}(\mathrm{mL})$ & Time (h) & Conv. (\%) & $M_{\mathrm{n}, \mathrm{th}}^{b}\left(\mathrm{~g} \mathrm{~mol}^{-1}\right)$ & $M_{\mathrm{n}, \mathrm{GPC}}\left(\mathrm{g} \mathrm{mol}^{-1}\right)$ & $M_{\mathrm{w}} / M_{\mathrm{n}}$ \\
\hline 1 & 1.0 & 0.5 & 26 & 91.2 & 9400 & 9500 & 1.30 \\
\hline 2 & 0.5 & 0.5 & 24 & 70.2 & 7200 & 8000 & 1.74 \\
\hline 4 & 0.1 & 0.5 & 24 & 99.9 & 10200 & 13200 & 1.67 \\
\hline 5 & 0 & 0.5 & 24 & 99.9 & 20200 & 70100 & 2.07 \\
\hline 6 & 1.0 & 0 & 24 & 34.0 & 3600 & 7700 & 2.00 \\
\hline 9 & 1.0 & 1.0 & 30 & 92.4 & 9500 & 8200 & 1.46 \\
\hline $10^{c}$ & 1.0 & 0.5 & 30 & 31.5 & - & 111000 & 1.43 \\
\hline $11^{d}$ & 1.0 & 0.5 & 24 & 0 & - & - & - \\
\hline
\end{tabular}

${ }^{a}$ Polymerization conditions: $R=[\mathrm{MMA}]_{0}:[\mathrm{EBPA}]_{0}:\left[\mathrm{FeBr}_{2}\right]_{0}=100: 1: x, V_{\mathrm{MMA}}=1.0 \mathrm{~mL}$, at room temperature under UV irradiation $\left(900 \mu \mathrm{W} \mathrm{cm}{ }^{-2}\right)$ at $360 \mathrm{~nm} .{ }^{b} M_{\mathrm{n}, \mathrm{th}}=\left([\mathrm{M}]_{0} /[\mathrm{I}]_{0}\right) \times M_{\mathrm{n}, \mathrm{MMA}} \times$ conv. $\%+M_{\mathrm{n}, \mathrm{EBPA}} \cdot{ }^{c}$ No EBPA was added. ${ }^{d}$ Without irradiation.

the molecular weight distribution $\left(M_{\mathrm{w}} / M_{\mathrm{n}}\right)$ became broader and the molecular weight $\left(M_{\mathrm{n}, \mathrm{GPC}}\right)$ deviated from its corresponding theoretical value $\left(M_{\mathrm{n}, \mathrm{th}}\right)$ gradually, indicating that the controllability of the polymerization system decreased correspondingly. When no $\mathrm{FeBr}_{2}$ was added, the polymerization exhibited loss of control, as the molecular weight distribution reached up to 2.07 and the $M_{\mathrm{n}, \mathrm{GPC}}$ deviated significantly from $M_{\mathrm{n}, \mathrm{th}}$. In this polymerization system, DMI acted as both the ligand and the solvent, so the volume of DMI should have a significant influence on the polymerization. From Table 1, we can see that when the volume of DMI was relatively low $(0.2 \mathrm{~mL})$, the rate of the polymerization was relatively slow. When the amount of DMI was increased to more than $0.8 \mathrm{~mL}$, the controllability of the polymerization was not desirable (entries 7-9 in Table 1). When $V_{\mathrm{DMI}}=0.5 \mathrm{~mL}$, the polymerization could be controlled well (entry 1 in Table 1). When no DMI was added, the molecular weight distribution reached up to 2.00 , which meant that the whole polymerization system was not controlled (entry 6 in Table 1). It is worth noting that even though no EBPA was added, the polymerization could still proceed (entry 10 in Table 1) because the monomer (MMA) can react with the iron catalyst and generate MMA-Br, which acts as an initiator in the polymerization system. ${ }^{17}$ However, the molecular weight $\left(111000 \mathrm{~g} \mathrm{~mol}^{-1}\right)$ was uncontrollable in this case. Furthermore, when the experiment was conducted without irradiation, no polymer was found after 24 hours (entry 11 in Table 1), indicating that UV irradiation plays an important role in the polymerization system.

\subsection{Effect of the amount of initiator on polymerization}

In order to investigate the effect of polymerization degree, we kept the amount of MMA, $\mathrm{FeBr}_{2}$ and the solvent constant, but changed the amount of initiator to conduct the polymerization. The results are shown in Table 2. It can be seen that even when the target degree of polymerization was up to $1000(x=0.1$, entry 3 in Table 2), the resultant molecular weight distribution was still narrow $\left(M_{\mathrm{w}} / M_{\mathrm{n}}=1.28\right)$ and $M_{\mathrm{n}, \mathrm{GPC}}\left(40800 \mathrm{~g} \mathrm{~mol}^{-1}\right)$ was close to its corresponding $M_{\mathrm{n}, \mathrm{th}}\left(35000 \mathrm{~g} \mathrm{~mol}^{-1}\right.$ ), indicating kind controllability of the polymerization system. Therefore, this method could be employed to synthesized polymers with relatively high molecular weight.
Table 2 Effect of the amount of initiator on the photo-induced ATRP of $\mathrm{MMA}^{a}$

\begin{tabular}{llllll}
\hline Entry & $x$ & Conv. $(\%)$ & $M_{\mathrm{n}, \mathrm{th}}{ }^{b}\left(\mathrm{~g} \mathrm{~mol}^{-1}\right)$ & $M_{\mathrm{n}, \mathrm{GPC}}\left(\mathrm{g} \mathrm{mol}^{-1}\right)$ & $M_{\mathrm{w}} / M_{\mathrm{n}}$ \\
\hline 1 & 0.5 & 57.5 & 11700 & 11600 & 1.28 \\
2 & 0.25 & 48.9 & 19800 & 20300 & 1.28 \\
3 & 0.1 & 40.6 & 40800 & 35000 & 1.28
\end{tabular}

${ }^{a}$ Polymerization conditions: $R=[\mathrm{MMA}]_{0}:[\mathrm{EBPA}]_{0}:\left[\mathrm{FeBr}_{2}\right]_{0}=$ $100: x: 1, V_{\mathrm{MMA}}=1.0 \mathrm{~mL}$, at room temperature under UV irradiation $\left(900 \mu \mathrm{W} \mathrm{cm}{ }^{-2}\right)$ at $360 \mathrm{~nm}$, time $=24 \mathrm{~h} .^{b} M_{\mathrm{n}, \mathrm{th}}=\left([\mathrm{M}]_{\mathrm{o}} /[\mathrm{I}]_{0}\right) \times M_{\mathrm{n}, \mathrm{MMA}}$ $\times$ conv. $\%+M_{\mathrm{n}, \mathrm{EBPA}}$.

\subsection{Polymerization kinetics of photo-induced Fe-based ATRP of MMA}

In order to deeply investigate the polymerization behavior, the polymerization kinetics of the system with the molar ratio of $[\mathrm{MMA}]_{0}:[\mathrm{EBPA}]_{0}:\left[\mathrm{FeBr}_{2}\right]_{0}=100: 1: 1$ was conducted at room

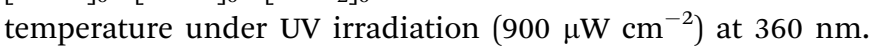
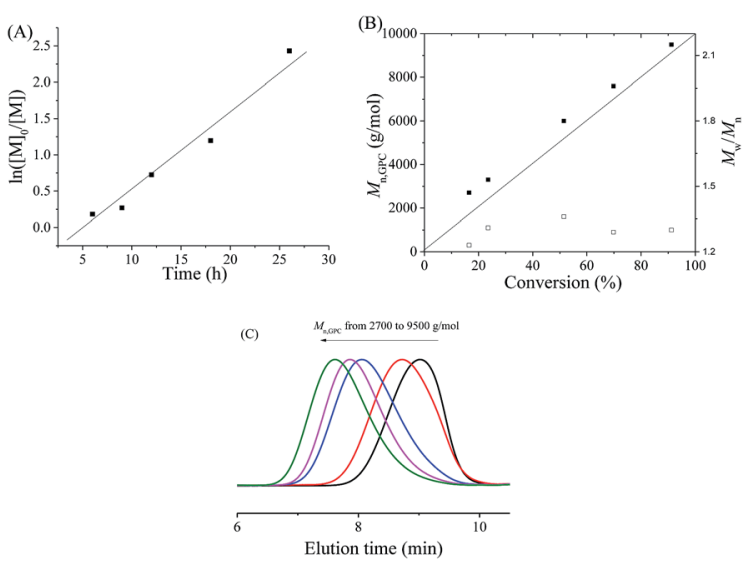

Fig. $1 \ln \left([M]_{0} /[M]\right)$ as a function of time $(A)$; evolution of numberaverage molecular weight $\left(M_{n, G P C}\right)$ and molecular weight distribution $\left(M_{w} / M_{n}\right)$ versus conversion (B); GPC elution curves (C) for Fe-based photo-induced ATRP of MMA. Polymerization conditions: [MMA] $]_{O^{-}}$ $:\left[\mathrm{EBPA}_{0}:\left[\mathrm{FeBr}_{2}\right]_{0}=100: 1: 1, V_{\mathrm{MMA}}=1.0 \mathrm{~mL}, V_{\mathrm{DMI}}=0.5 \mathrm{~mL}\right.$, at room temperature under UV irradiation $\left(900 \mu \mathrm{W} \mathrm{cm}{ }^{-2}\right)$ at $360 \mathrm{~nm}$. 


$$
\mathrm{R}-\mathrm{X}+\mathrm{Fe}^{\mathrm{II}} \cdots \text { (solvent) } \frac{\mathrm{hV}}{k_{d a}}
$$

Scheme 1 Possible polymerization mechanism of photo-induced Febased ATRP under irradiation of UV light.

The first-order curve consisting of time and $\ln \left([\mathrm{M}]_{0} /[\mathrm{M}]\right)$, shown in Fig. 1A, indicates that the propagation radical concentration remained approximately constant during polymerization. Furthermore, the molecular weights $\left(M_{\mathrm{n}, \mathrm{GPC}} \mathrm{S}\right)$ were close to the corresponding theoretical values $\left(M_{\mathrm{n}, \mathrm{th}} \mathrm{S}\right)$ and increased linearly with the monomer conversion, while maintaining narrow molecular weight distributions at the same time (Fig. 1B). Moreover, the GPC elution curves (Fig. 1C) show a distinct shift from low molecular weights to high molecular weights during the polymerization. All of these results confirmed the "living" features of this photo-induced Fe-based ATRP system. In addition, the possible polymerization mechanism of photo-induced Fe-based ATRP is shown in Scheme 1, which is based a reversible dynamic equilibrium between the active $\mathrm{Fe}(\mathrm{II})$ species and the deactivator $\mathrm{Fe}(\mathrm{III})$ species under irradiation of UV light.

\subsection{Analysis of chain-end and chain extension}

The chain-end of the resultant PMMA was analyzed by ${ }^{1} \mathrm{H}$ NMR spectroscopy in DMSO-d6. The chemical shifts at $\delta=0.5-2.0$
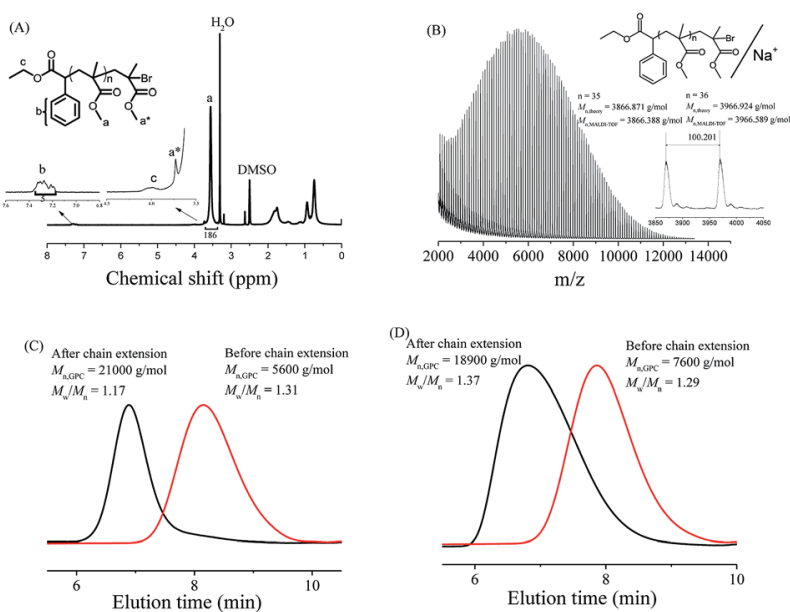

Fig. $2{ }^{1} \mathrm{H}$ NMR spectrum (A) and MALDI-TOF MS (B) of the resultant PMMA. Polymerization conditions of sample PMMA $\left(M_{n, G P C}=6900 \mathrm{~g}\right.$ $\left.\mathrm{mol}^{-1}, M_{\mathrm{n}, \mathrm{NMR}}=6400 \mathrm{~g} \mathrm{~mol}^{-1}, M_{\mathrm{w}} / M_{\mathrm{n}}=1.35\right):[\mathrm{MMA}]_{0}:[\mathrm{EBPA}]_{0^{-}}$ $:\left[\mathrm{FeBr}_{2}\right]_{0}=100: 1: 1, V_{\mathrm{MMA}}=1.0 \mathrm{~mL}, V_{\mathrm{DMI}}=0.5 \mathrm{~mL}$, time $=15 \mathrm{~h}$, at room temperature under UV irradiation $\left(900 \mu \mathrm{W} \mathrm{cm}{ }^{-2}\right)$ at $360 \mathrm{~nm}$. GPC traces of PMMA before and after chain extension under both photoinduced (C) and thermal (D) conditions. Chain extension conditions via photochemical reaction: $[\mathrm{MMA}]_{0}:[\mathrm{PMMA}]_{0}:\left[\mathrm{FeBr}_{2}\right]_{0}=100: 0.4: 1$, $V_{\text {MMA }}=1.0 \mathrm{~mL}, V_{\mathrm{DMl}}=0.5 \mathrm{~mL}$, time $=54 \mathrm{~h}$, at room temperature under UV irradiation $\left(900 \mu \mathrm{W} \mathrm{cm}{ }^{-2}\right)$ at $360 \mathrm{~nm}$. Chain extension conditions via thermal polymerization reaction: $[\mathrm{MMA}]_{0}:[\mathrm{PMMA}]_{0}:\left[\mathrm{Fe}(\mathrm{acac})_{3}\right]_{0}$ : $\left[\mathrm{PPh}_{3}\right]_{0}:[\mathrm{AsAc}]_{0}=100: 0.4: 1: 3: 4, V_{\mathrm{MMA}}=1.0 \mathrm{~mL}, V_{\text {toluene }}=1.0 \mathrm{~mL}$, $T=70{ }^{\circ} \mathrm{C}$, time $=24 \mathrm{~h}$. ppm (d in Fig. 2A) were assigned to methylene group in PMMA and methyl group in PMMA and the initiator moieties of EBPA. The chemical shifts at $\delta=4.0 \mathrm{ppm}$ (c in Fig. 2A) and 7.2$7.4 \mathrm{ppm}$ (b in Fig. 2A) were attributed to the methylene and phenyl groups in the initiator moieties of EBPA. The chemical shift at $\delta=3.6 \mathrm{ppm}$ (a in Fig. 2A) was assigned to the methyl ester groups in PMMA. The signal at $\delta=3.78 \mathrm{ppm}$ (a* in Fig. 2A) was assigned to methyl ester groups at the chain-end. Further, MALDI-TOF MS was conducted to analyze the structure of PMMA. As shown in Fig. 2B, the main series of peaks was assigned to PMMA with EBPA moieties attached to the end. The interval (100.201 of $\mathrm{m} / \mathrm{z}$ ) between every two peaks represents the MMA unit.

Finally, chain extension experiments were conducted to verify the living features of the photo-induced Fe-based ATRP of MMA. Firstly, we conducted a chain extension experiment using the resultant PMMA as the macroinitiator $\left(M_{\mathrm{n}, \mathrm{GPC}}=5600 \mathrm{~g}\right.$ $\left.\mathrm{mol}^{-1}, M_{\mathrm{w}} / M_{\mathrm{n}}=1.31\right)$ to carry out the photo-induced Fe-based ATRP of MMA. As shown in Fig. 2C, the $M_{\mathrm{n}, \mathrm{GPC}}$ increased from $5600 \mathrm{~g} \mathrm{~mol}^{-1}$ to $21000 \mathrm{~g} \mathrm{~mol}^{-1}$ after chain extension. Secondly, a thermal AGET ATRP of MMA was conducted using the resultant PMMA as the macroinitiator $\left(M_{\mathrm{n}, \mathrm{GPC}}=7600 \mathrm{~g} \mathrm{~mol}^{-1}, M_{\mathrm{w}} /\right.$ $\left.M_{\mathrm{n}}=1.29\right)$. As shown in Fig. $2 \mathrm{D}$, the $M_{\mathrm{n}, \mathrm{GPC}}$ increased from $7600 \mathrm{~g} \mathrm{~mol}^{-1}$ to $18900 \mathrm{~g} \mathrm{~mol}^{-1}$ after chain extension. These two chain extension experiments indicate that the PMMA obtained via the photo-induced Fe-based ATRP had a high degree of chain-end functionality.

\section{Conclusions}

A highly efficient photo-induced Fe-based ATRP of MMA was developed using "green" DMI as both the ligand and solvent without any additional ligands. The rate of the polymerization was relatively fast and well controlled polymers could be facilely obtained.

\section{Acknowledgements}

The financial support from the National Natural Science Foundation of China (No. 21174096, 21674071), the Project of Science and Technology Development Planning of Jiangsu Province (No. BK20141192) and the Project Funded by the Priority Academic Program Development of Jiangsu Higher Education Institutions (PAPD) are gratefully acknowledged.

\section{Notes and references}

1 (a) W. A. Braunecker and K. Matyjaszewski, Prog. Polym. Sci., 2007, 32, 93; (b) A. Goto and T. Fukuda, Prog. Polym. Sci., 2004, 29, 329; (c) K. Matyjaszewski and T. P. Davis, Handbook of Radical Polymerization, John Wiley \& Sons, Inc., Hoboken, NJ, 2002; (d) R. Poli, L. E. N. Allan and M. P. Shaver, Prog. Polym. Sci., 2014, 39, 1827; (e) V. Sciannamea, R. Jerome and C. Detrembleur, Chem. Rev., 2008, 108, 1104; (f) T. Öztürk, M. N. Atalar, M. Göktaş and B. Hazer, J. Polym. Sci.: Part A: Polym. Chem., 2013, 51, 2651. 
2 (a) M. Kato, M. Kamigaito, M. Sawamoto and T. Higashimura, Macromolecules, 1995, 28, 1721; (b) J. S. Wang and K. Matyjaszewski, J. Am. Chem. Soc., 1995, 117, 5614; (c) K. Matyjaszewski and J. H. Xia, Chem. Rev., 2001, 101, 2921; (d) M. Ouchi, T. Terashima and M. Sawamoto, Chem. Rev., 2009, 109, 4963; (e) M. F. Cunningham, Prog. Polym. Sci., 2008, 33, 365; $(f)$ W. W. He, H. J. Jiang, L. F. Zhang, Z. P. Cheng and X. L. Zhu, Polym. Chem., 2013, 4, 2919; $(g)$ L. J. Bai, L. F. Zhang, Z. P. Cheng and X. L. Zhu, Polym. Chem., 2012, 3, 2685-2697; (h) H. Arslan, N. Yeşilyurt and B. Hazer, J. Appl. Polym. Sci., 2007, 106, 1742; (i) T. Öztürk, S. S. Yilmaz, B. Hazer and Y. Z. Menceloglu, J. Polym. Sci.: Part A: Polym. Chem., 2010, 48, 1364.

3 (a) D. Q. Qin, S. H. Qin, X. P. Chen and K. Y. Qiu, Polymer, 2000, 41, 7347; (b) J. S. Wang and K. Matyjaszewski, Macromolecules, 1995, 28, 7572; (c) Y. P. Wang, X. W. Pei, X. Y. He and K. Yuan, Eur. Polym. J., 2005, 41, 1326; (d) Z. P. Cheng, X. L. Zhu, G. J. Chen, W. J. Xu and J. M. Lu, J. Polym. Sci., Part A: Polym. Chem., 2002, 40, 3823; (e) Z. P. Cheng, X. L. Zhu, L. F. Zhang, N. C. Zhou and J. Y. Chen, J. Macromol. Sci., Part A: Pure Appl. Chem., 2003, A40, 371; $(f)$ G. H. Zhu, L. F. Zhang, X. Q. Pan, W. Zhang, Z. P. Cheng and X. L. Zhu, Macromol. Rapid Commun., 2012, 33, 2121.

4 (a) L. J. Bai, L. F. Zhang, J. L. Pan, J. Zhu, Z. P. Cheng and X. L. Zhu, Macromolecules, 2013, 46, 2060; (b) W. Jakubowski and K. Matyjaszewski, Macromolecules, 2005, 38, 4139; (c) L. Mueller, W. Jakubowski, K. Matyjaszewski, J. Pietrasik, P. Kwiatkowski, W. Chaladaj and J. Jurczak, Eur. Polym. J., 2011, 47, 730.

5 (a) T. Guo, L. F. Zhang, X. Q. Pan, X. H. Li, Z. P. Cheng and X. L. Zhu, Polym. Chem., 2013, 4, 3725; (b) K. Mukumoto, Y. Wang and K. Matyjaszewski, ACS Macro Lett., 2012, 1, 599; (c) L. F. Zhang, J. Miao, Z. P. Cheng and X. L. Zhu, Macromol. Rapid Commun., 2010, 31, 275; (d) G. H. Zhu, L. F. Zhang, Z. B. Zhang, J. Zhu, Y. F. Tu, Z. P. Cheng and X. L. Zhu, Macromolecules, 2011, 44, 3233; (e) X. W. Jiang, J. Wu, L. F. Zhang, Z. P. Cheng and X. L. Zhu, Macromol. Rapid Commun., 2014, 35, 1879; (f) B. J. Zhang, X. W. Jiang, L. F. Zhang, Z. P. Cheng and X. L. Zhu, Polym. Chem., 2015, 6, 6616; (g) X. W. Jiang, L. F. Zhang, Z. P. Cheng and X. L. Zhu, Macromol. Rapid Commun., 2016, 37, 1337.

6 (a) N. J. Treat, H. Sprafke, J. W. Kramer, P. G. Clark, B. E. Barton, J. R. de Alaniz, B. P. Fors and C. J. Hawker, J. Am. Chem. Soc., 2014, 136, 16096; (b) G. M. Miyake and J. C. Theriot, Macromolecules, 2014, 47, 8255; (c) X. C. Pan, M. Lamson, J. J. Yan and K. Matyjaszewski, ACS Macro Lett., 2015, 4, 192; (d) X. Pan, C. Fang, M. Fantin, N. Malhotra, W. Y. So, L. A. Peteanu, A. A. Isse, A. Gennaro, P. Liu and K. Matyjaszewski, J. Am. Chem. Soc., 2016, 138, 2411; (e) J. C. Theriot, C. H. Lim, H. Yang, M. D. Ryan, C. B. Musgrave and G. M. Miyake, Science, 2016, 352, 1082; (f) X. D. Liu, L. F. Zhang, Z. P. Cheng and X. L. Zhu, Polym. Chem., 2016, 7, 689; $(g)$ R. M. Pearson, C. Lim, B. G. McCarthy, C. B. Musgrave and G. M. Miyake, J. Am. Chem. Soc., 2016, 138, 11399; (h) A. Allushi, S. Jockusch,
G. Yilmaz and Y. Yagci, Macromolecules, 2016, 49, 7785; (i) J. Wang, L. Yuan, Z. Wang, M. A. Rahman, Y. Huang, T. Zhu, R. Wang, J. Cheng, C. Wang, F. Chu and C. Tang, Macromolecules, 2016, 49, 7709; (j) J. Yan, X. Pan, M. Schmitt, Z. Wang, M. R. Bockstaller and K. Matyjaszewski, ACS Macro Lett., 2016, 5, 661; (k) S. Jockusch and T. Yagci, Polym. Chem., 2016, 7, 6039; $(l)$ Z. C. Huang, Y. Gu, X. D. Liu, L. F. Zhang, Z. P. Cheng and X. L. Zhu, Macromol. Rapid Commun., 2016, DOI: 10.1002/ marc.201600461d.

7 (a) J. Queffelec, S. G. Gaynor and K. Matyjaszewski, Macromolecules, 2000, 33, 8629; (b) W. X. Wang, Z. B. Zhang, Z. P. Cheng, J. Zhu, N. C. Zhou and X. L. Zhu, Polym. Chem., 2012, 3, 2731; (c) L. J. Bai, W. X. Wang, M. H. Wang, J. M. Sun and H. Chen, Chin. J. Polym. Sci., 2015, 33, 1260; (d) X. W. Jiang, J. Wu, L. F. Zhang, Z. P. Cheng and X. L. Zhu, Macromol. Rapid Commun., 2016, 37, 143; (e) M. Q. Ding, X. W. Jiang, J. Y. Peng, L. F. Zhang, Z. P. Cheng and X. L. Zhu, Macromol. Rapid Commun., 2015, 36, 538; (f) X. W. Jiang, Y. J. Luo, Z. Li, L. F. Zhang, Z. P. Cheng and X. L. Zhu, Polym. Chem., 2015, 6, 6394; (g) Z. C. Huang, J. Chen, L. F. Zhang, Z. P. Cheng and X. L. Zhu, Polymers, 2016, 8(3), 59.

8 (a) G. Moineau, M. Minet, P. Dubois, P. Teyssie, T. Senninger and R. Jerome, Macromolecules, 1999, 32, 27; (b) C. Moineau, M. Minet, P. Teyssie and R. Jerome, Macromolecules, 1999, 32, 8277; (c) R. M. Johnson, P. S. Corbin, C. Ng and C. L. Fraser, Macromolecules, 2000, 33, 7404.

9 (a) J. H. Xia, H. J. Paik and K. Matyjaszewski, Macromolecules, 1999, 32, 8310; (b) L. E. N. Allan, J. P. MacDonald, A. M. Reckling, C. M. Kozak and M. P. Shaver, Macromol. Rapid Commun., 2012, 33, 414; (c) L. J. Bai, L. F. Zhang, Z. B. Zhang, J. Zhu, N. C. Zhou, Z. P. Cheng and X. L. Zhu, J. Polym. Sci., Part A: Polym. Chem., 2011, 49, 3980; (d) W. W. He, L. F. Zhang, J. Miao, Z. P. Cheng and X. L. Zhu, Macromol. Rapid Commun., 2012, 33, 1067; (e) J. L. Pan, Z. Li, L. F. Zhang, Z. P. Cheng and X. L. Zhu, Chin. J. Polym. Sci., 2014, 32, 1010; (f) J. Wu, X. W. Jiang, L. F. Zhang, Z. P. Cheng and X. L. Zhu, Polymers, 2016, 8(2), 29; (g) X. D. Liu, Q. Chen, G. B. Yang, L. F. Zhang, Z. Liu, Z. P. Cheng and X. L. Zhu, J. Mater. Chem. B, 2015, 3, 2786.

10 (a) L. J. Bai, W. X. Wang, H. Chen, L. F. Zhang, Z. P. Cheng and X. L. Zhu, RSC Adv., 2015, 5, 62577; (b) K. Nishizawa, M. Ouchi and M. Sawamoto, Macromolecules, 2013, 46, 3342; (c) H. Schroeder, K. Matyjaszewski and M. Buback, Macromolecules, 2015, 48, 4431; (d) Z. G. Xue, D. He and X. L. Xie, Polym. Chem., 2015, 6, 1660.

11 (a) S. Nakanishi, M. Kawamura, H. Kai, R. H. Jin, Y. Sunada and H. Nagashima, Chem.-Eur. J., 2014, 20, 5802; (b) L. F. Zhang, Z. P. Cheng, Y. T. Lu and X. L. Zhu, Macromol. Rapid Commun., 2009, 30, 543.

12 (a) Z. J. Deng, J. N. Guo, L. H. Qiu, C. Yuan, Y. X. Zhou and F. Yan, J. Polym. Sci., Part A: Polym. Chem., 2013, 51, 664; (b) S. M. Zhu and D. Y. Yan, Macromol. Rapid Commun., 2000, 21, 1209. 
13 M. Q. Ding, X. W. Jiang, J. Y. Peng, L. F. Zhang, Z. P. Cheng and X. L. Zhu, Green Chem., 2015, 17, 271.

14 (a) Y. Wang and K. Matyjaszewski, Macromolecules, 2010, 43, 4003; (b) Z. G. Xue, J. Zhou, D. He, F. Wu, D. F. Yang, Y. S. Ye, Y. G. Liao, X. P. Zhou and X. L. Xie, Dalton Trans., 2014, 43, 16528.

15 B. P. Fors and C. J. Hawker, Angew. Chem., Int. Ed., 2012, 51, 8850.
16 D. Konkolewicz, K. Schroder, J. Buback, S. Bernhard and K. Matyjaszewski, ACS Macro Lett., 2012, 1, 1219.

17 X. C. Pan, N. Malhotra, J. N. Zhang and K. Matyjaszewski, Macromolecules, 2015, 48, 6948.

18 (a) A. Takaragi, M. Minoda, T. Miyamoto, H. Q. Liu and L. N. Zhang, Cellulose, 1999, 6, 93; (b) K. I. Yamashita, M. Tsuboi, M. S. Asano and K. Sugiura, Synth. Commun., 2012, 42, 170; (c) Y. F. Tie, D. J. Wu, R. Q. Sun, P. Y. Shen and Y. L. Wang, Chin. J. Synth. Chem., 2000, 8, 301. 